\title{
Restoration of houbara bustard populations in Saudi Arabia: developments and future directions
}

\author{
P. J. Seddon, M. Saint Jalme, Y. van Heezik, P. Paillat, P. Gaucher and \\ O. Combreau
}

\begin{abstract}
The National Commission for Wildlife Conservation and Development (NCWCD) was established in 1986 to oversee all wildlife conservation programmes in Saudi Arabia. One of the first species-specific programmes, started in the same year, was a houbara bustard Chlamydotis undulata macqueenii captive-breeding project at the National Wildlife Research Center. With the production in 1992 of a selfsustaining captive houbara flock and the provision of an annual surplus of houbara chicks, attention has shifted to the release of captive-bred houbara into protected areas. Critical review of the houbara programme in 1993 emphasized the need for field studies, public-awareness programmes and international collaboration in addition to captive-rearing and release.
\end{abstract}

\section{Introduction}

If, to paraphrase Rodger Tory Peterson (1948), 'Man has emerged from the shadows of antiquity with a (falcon) on his wrist', then in the Arabian Peninsula at least, there was probably a houbara bustard Chlamydotis undulata somewhere nearby. Through its status as the premier target for the ancient sport of falconry, the houbara has attained a prominence in Middle Eastern conservation programmes beyond any possible value as a keystone or indicator species. In Saudi Arabia, efforts to conserve the houbara serve to focus public attention on wider conservation issues and help ensure the success of other, lower profile, species-conservation programmes.

Three subspecies of houbara bustard are recognized: $C$. $u$. fuertaventurae, resident in the Canary Islands; C. $u$. undulata, resident or locally dispersive in North Africa; and C. u. macqueenii, the Asiatic subspecies, resident in southern parts of its breeding range from the Arabian Peninsula across to the Indian subcontinent, but migratory in Central Asia (Cramp and Simmons, 1980). There is little reliable information on the exact status of houbara populations, but they are generally considered to have suffered marked declines over most of their range during the last few decades (Collar, 1980). These declines have been attributed primarily to overhunting and, secondarily, to habitat degradation through overgrazing and agricultural development. One exception to this general trend may be populations of C. u. macqueenii in Kazakhstan, estimates of which range in the tens of thousands (Gubin, in press). The official IUCN category for the houbara is Vulnerable (V), which includes populations that are seriously depleted, or decreasing due to overexploitation or other factors, and are at risk of becoming Endangered (E) if causal factors continue unchecked (IUCN, 1990).

In 1986, in recognition of perceived declines in houbara C. u. macqueenii numbers, and with the intention of conserving the houbara as a breeding species in Saudi Arabia, His Royal Highness Prince Saud Al Faisal established both the National Wildlife Center's houbara captive-breeding project, and the National Commission for Wildlife Conservation and Development to oversee the preservation, protection and development of wildlife 
Figure 1. Protected areas of importance to the houbara bustard restoration programme in Saudi Arabia.

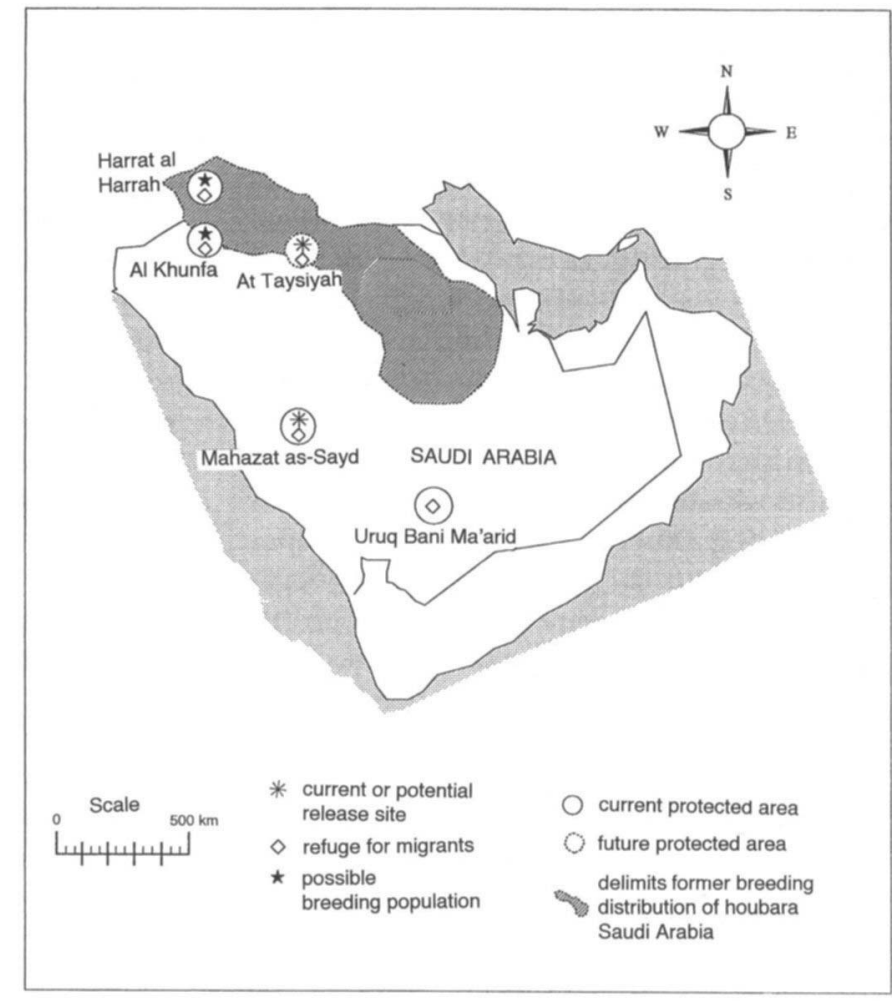

populations within Saudi Arabia (Abuzinada et al., 1989).

\section{Status of the houbara and its habitat in Saudi Arabia}

The historical decline of the houbara in Saudi Arabia is not well documented. The problems associated with estimating the relative abundance of this cryptic and mobile bird are compounded by the probability that there are two overlapping populations. Current understanding of the distribution and movements of houbara suggests that Saudi Arabia contains both resident and migrant populations. The distinctness of these two populations is not known. It is possible that at the southern limits of the breeding range of migrant houbara, migrants may breed sympatrically, or interbreed with so-called residents.

\section{Resident houbara}

Early written accounts of houbara breeding distribution in Saudi Arabia come from European explorers in the region and delimit a probable former core breeding range (Figure 1) in the north of the Kingdom (Jennings, 1988, 1989). Today there is only one confirmed locality where houbara may be found all year round and in which breeding attempts occur in most years - the Harrat al-Harrah protected area in the $\mathrm{Al}$ Jouf Emirate, in the extreme north-west (Figure 1). Harrat al-Harrah was declared a Special Natural Reserve in 1987 by the NCWCD Board of Directors. This resulted in the protection of $13,775 \mathrm{sq} \mathrm{km}$ of undulating olivine basalt lava field (harrat). Harrat alHarrah was chosen to protect possibly one of the last breeding populations of houbara in Saudi Arabia, as well as a population of sand gazelle Gazella subgutturosa (Child and Grc inger, 1990). Estimates of the total resident 
population of houbara in Harrat al-Harrah range from $70-80$ (Goriup, in press), to approximately 300 birds (based on an extrapolation from densities recorded within a core study area; Seddon and van Heezik, in prep.). The available evidence suggests that in the 6 years since grazing livestock were reduced and hunting was forbidden within the reserve, the number of houbara breeding in Harrat alHarrah has not increased demonstrably (NCWCD, unpubl. data). Inter-annual differences in the number of nests located appears to reflect variation in the amount and distribution of spring rainfall rather than actual population trends. It is possible that Harrat alHarrah retains a remnant population of houbara by virtue of its remoteness and inaccessibility, rather than because it provides optimal habitat.

\section{Migrant houbara}

Migrant houbara may be found in Saudi Arabia each year during the non-breeding period, with the largest flocks observed during winter (November-January) (Seddon and van Heezik, in prep.). The origin of houbara arriving in Saudi Arabia is not known. A single record exists of houbara caught and ringed in Harrat al-Harrah, and recovered (killed) in Syria (P. Goriup, pers. comm.). During the winter migrant houbara appear to disperse throughout the Kingdom. It is these birds that form the basis of the limited falconry that still occurs between December and February each year. It is possible, but as yet unproven, that migrant houbara may breed within Saudi Arabia in years with good spring rainfall. The possible contribution migrant houbara may make to so-called resident populations is unknown.

\section{Habitat protection}

Harrat al-Harrah is the only protected area to have been established primarily to protect remnant houbara populations. As recently as spring 1993 houbara breeding was recorded in the Al-Khunfah protected area (Figure 1), a gazelle reserve of over $20,000 \mathrm{sq} \mathrm{km}$, north of the Great Nafud sand desert. The borders of Harrat al-Harrah and Al-Khunfah are patrolled daily by a permanent force of rangers and by light aircraft. Both Al-Khunfah and AlHarrah lie within a larger no-hunting zone. Also available as refugia for migrant houbara are the Mahazat as-Sayd reserve, site of the first captive-bred houbara reintroduction trials, and the Uruq Bani Ma' arid reserve, a reintroduction site for Arabian oryx Oryx leucoryx. Migrant houbara have been recorded in Mahazat as recently as winter 1992, and in Ma'arid in February of 1994.

\section{Saudi Arabia's houbara restoration programme}

The houbara bustard restoration programme has the long-term goal of securing self-sustaining populations of houbara within a network of managed sites in Saudi Arabia. The houbara programme in Saudi Arabia has attracted some criticism in the past because of uncertainty surrounding the motivation for the project, namely is this a conservation project, or merely an elaborate means to provide birds for an elite group of falconers? Saudi Arabia's houbara restoration programme was conceived and proceeds with the principal objective of conserving the houbara bustard in Saudi Arabia and preventing the local extinction of the species as a breeding population. While future sustainable use of houbara for regulated traditional falconry remains a possibility, the basis of conservation efforts is the creation and management of strictly patrolled protected areas within larger no-hunting zones. The conservation intent of the programme is supported at all levels within the National Wildlife Commission.

The programme has two components: the conservation of wild houbara, resident and migratory; and the reintroduction into suitable habitat of captive-bred houbara.

\section{Conservation of wild houbara}

The basis of Saudi Arabian conservation programmes for the houbara and other endan- 
gered species is the NCWCD's Protected Area System Plan (Child and Grainger, 1990), which details a process for identification, protection and management of key areas containing representative portions of major biotopes, or examples of threatened taxa. Crucial in the identification of sites suitable for houbara is the characterization of optimal houbara habitat. Many qualitative descriptions of houbara habitat throughout the species's range are available in the literature. These are useful for the broadest scale classification of habitat suitability, taking into account geographic, topographic and climatic features, and major plant associations. The classification of finer-scale habitat requirements in Saudi Arabia is hampered by the reduction in the breeding range of the houbara, and the degree of habitat degradation. At present the conservation of wild houbara depends on the identification and protection of breeding sites such as Harrat al-Harrah, within which studies of habitat use by wild birds will guide the identification of new areas for protection. These new areas will be available as refugia for migrant houbara, and as reintroduction sites for captive-bred houbara.

Hunting of houbara is forbidden by any means other than falcon, and even then is restricted to December-February each year. Hunting is forbidden within protected areas and within the large no-hunting zones that encompass the northern protected areas. However, at present there are no limits on the numbers of hunters, numbers of falcons, or numbers of houbara taken by falcon, nor any system of registration of legal hunters. No records are available with which to assess the current seasonal impact of falconry on houbara in Saudi Arabia. Penalties for hunting violations are considered insufficiently severe to deter poaching. Saudi Arabia's hunting laws are currently under revision.

At the international level, Saudi Arabia is a signatory to the Bonn Convention for the conservation of migratory species. The NCWCD has indicated its intention to draft an International Agreement and Management Plan with the aim of consolidating efforts to conserve the houbara throughout its range.
This calls on range states to take measures to improve the local status of houbara. A working document of this draft Agreement was presented at the ICBP World Conference in New Zealand in 1990, and a revised draft is currently under consideration.

\section{Captive-breeding}

Following attempts to breed the houbara in captivity in France in 1985 (Renaud, 1989), a large-scale operation was established at the NWRC near Taif in early 1986. The original breeding stock consisted of 103 chicks of the Asian subspecies, and 129 chicks of the African subspecies hatched from eggs collected under permit during authorized expeditions to Pakistan and Algeria between 1986 and 1988. The African subspecies is inappropriate for release in Saudi Arabia and has been used in experiments to improve captivebreeding techniques, and as surrogate mothers for Asiatic houbara chicks. The foundation of a captive-flock of hand-reared houbara was necessary in order to have birds tame enough for handling, artificial insemination and egg manipulation procedures.

Getting houbara to breed in captivity was a difficult task given the paucity of information about the breeding behaviour of the species. The first breeding success was achieved in 1989. There were three reasons for this delay. First, the low rate of egg production by female houbara of only one to four eggs per year in the wild. Secondly, many female houbara will not reach sexual maturity and do not start laying until they are 3 years old. Finally, it appears that almost 18 per cent of female houbara are unable to become accustomed to captivity and will never lay (Saint Jalme et al., in press, a).

Experimentation with methods of eggpulling, artificial insemination (Saint Jalme et al., in press, $a, b)$ and artificial incubation, steadily increased chick production. The normal rate of egg production in the wild was increased in captivity by removing newly laid eggs and simulating re-laying. Using this method it has been possible to make females lay an average of nearly nine eggs each. A sin- 
gle female at the NWRC laid 30 eggs in one season. Artificial insemination raised the level of fertility from less than 50 to 82 per cent. Seventeen chicks were hatched in 1989, 138 in 1992, and 285 from 75 females in 1993. Details of the methods and results of the houbara captive-breeding programme are given in Saint Jalme et al. (in press, a)

Based on levels of fertility and hatchability obtained thus far, by keeping 50 female and 50 male houbara chicks as breeding stock each year, the NWRC houbara breeding unit plans to produce a surplus of 1000 chicks of the subspecies macqueenii annually by the year 2000 (Saint Jalme, in press).

\section{Release of captive-bred houbara}

Results from DNA sequencing (Gaucher et al., in prep.) indicate that the Asiatic houbara C. $u$. macqueenii is clearly distinguished from the North African undulata, at least to subspecific level. Comparisons between birds of known origin - from Sinai, Pakistan and northern Saudi Arabia - indicate that only the Sinai birds form a separate clade. Current analyses indicate that there is no genetic differentiation between houbaras from Pakistan and from Saudi Arabia. Therefore, founder breeding stock originating from Pakistan will have given rise to offspring that are genetically appropriate for release in Saudi Arabia.

The first release trials took place between July and August 1991 in the Mahazat as-Sayd reserve (Weigeldt et al., 1991). Three release methods were tried. The first, a hard release of two subadult houbara directly into the reserve, resulted in the predation by red fox Vulpes vulpes of both birds after 2 and 5 days, respectively. For the second release two feather-cut houbara were released into a predator-proof pre-release enclosure of $4 \mathrm{sq}$ $\mathrm{km}$. These birds were in moult and were expected to become flighted after approximately 1 month. After 1 week one bird managed to leave the enclosure and was killed by a red fox within 24 hours. The other bird remained within the enclosure for the duration of the study (58 days). The third method was the release of two 3-month old houbara into the pre- release enclosure. Both birds left the enclosure within 3 days. One was killed by a red fox 5 days later. The experiment was then terminated and the other bird was moved back into the pre-release enclosure.

These initial trials indicated a need to try 'soft' release methods, whereby naive captivebred houbara are given the opportunity to adjust gradually to the wild situation. This was attempted in a series of release trials started in 1992, using pre-release pens within the larger pre-release enclosure, and releasing 4-weekold chicks with females, 3-month-old chicks and 1-year-old birds. The results of these trials have been reported in detail elsewhere (Combreau et al., in press; Sainte Jalme et al., in press, a). Initial results indicate that releasing 3-month-old houbara may yield the highest survival rate, but that predation, presumably by red fox, remains a major problem.

\section{Future directions}

In October 1993 the NCWCD hosted an international workshop to review critically the progress and future direction of the houbara programme (Abuzinada and Seddon, in press). Workshop participants drafted recommendations for a conservation policy for the houbara in Saudi Arabia and a series of technical recommendations for the captive-rearing and release projects. These recommendations have become the basis for a conservation strategy for the houbara (Seddon, 1993), which is currently under review. In focusing on goals and objectives for management, in assigning specific personnel responsible for each objective, and with a system of regular progress assessment, the conservation strategy serves to guide the NCWCD in resource allocation.

The seven objectives of the strategy, which are listed below, attempt to achieve a balance between research and application, and between in situ and $e x$ situ methods.

1 To determine the distribution, status and trends of houbara populations in Saudi Arabia.

2 To improve understanding of houbara ecology. 
3 To protect and improve houbara habitat.

4 To maintain a houbara captive-breeding facility.

5 To develop techniques for the rearing and release of captive-bred houbara, and to investigate the potential for translocations of captive-bred houbara to augment or establish new populations, and to assist research.

6 Promote public awareness and foster public support for houbara conservation.

7 To take a lead in initiating co-operative conservation efforts between houbara range states.

\section{Habitat protection}

Currently scheduled for protection and use as possible houbara reintroduction sites is a substantial area within the houbara's former breeding range, in At-Taysiyah (4000 sq km), (Figure 1). An ungulate reintroduction site has been established at Uruq Bani Ma'arid (unfenced; borders undefined) (Figure 1) and will offer incidental protection to migrant houbara. An unfenced north-eastern extension of the Mahazat as-Sayd reserve is planned to increase the area of habitat available to both migrant and released houbara. Survey work within the former breeding range of the houbara started in 1994 with the aim of identifying potential sites for protection. This work will be expanded in 1995 to include surveys of the winter distribution of migrant houbara, also with a view to expansion of the protected area network.

\section{Field studies}

In general there is a need for more information on the distribution and ecology of houbara in Saudi Arabia. The former is being addressed through ground and aerial surveys, and the distribution of questionnaires. The latter is restricted at present to studies within the Harrat al-Harrah reserve where on-going work examines houbara diet, density, distribution and habitat use. Monthly counts of houbara and intensive searches for houbara nests each spring are also carried out there. Expansion of this work depends largely on the development of suitable techniques for trapping houbara, and tracking marked individuals; the use of nets, snares, trained falcons and helicopters is under investigation. To date only one Harrat al-Harrah houbara has been tracked using conventional radio-telemetry. In the absence of reliable trapping methods, the release and radio-monitoring of captive-bred houbara may provide the most efficient method of increasing our knowledge of houbara ecology.

Much useful information may be obtained through the NCWCD project by having trained personnel accompany hunting parties to collect demographic data on live birds, and morphometric and physiological information from migrant houbara caught by falcon outside the no-hunting zones. This work is due to begin in early 1995.

\section{Captive-rearing and release}

In 1994 a total of 40 captive-bred houbara were released into the Mahazat as-Sayd reserve, and work will soon begin on the preparation of a pre-release site in the At-Taysiyah protected area. In 1995 another 150 houbara chicks could be available for release into Mahazat. By 1996 up to 250 houbara chicks are scheduled to be available for release.

The problem of high levels of predation on released houbara by mammalian predators will be addressed in two ways. Experimental work has started to decrease predator density artificially by translocating red foxes from the vicinity of the pre-release enclosure in Mahazat as-Sayd. A more comprehensive study of mammalian predator-small mammal/houbara interactions is planned for 1995. For the second approach, during the 1994-95 houbara breeding season a variety of chickrearing regimens will be tried, including predator recognition training to improve the ability of captive-bred houbara to avoid predation.

\section{Acknowledgements}

Houbara conservation programmes in Saudi Arabia have been made possible through the initiatives of 
His Royal Highness Prince Saud Al Faisal and under the guidance of Dr Abdulaziz Abuzinada, Secretary General of the NCWCD. We would also like to thank J. Renaud and A. R. Khoja, NWRC General Manager and Administrative Director, respectively. An earlier draft benefited from the comments of two anonymous referees.

\section{References}

Abuzinada, A.H., Goriup, P.D. and Nader, I. (eds). 1989. Wildlife Conservation and Development in Saudi Arabia. Proceedings of the First Symposium, Riyadh, 1987. NCWCD, Riyadh, Saudi Arabia.

Abuzinada, A.H. and Seddon, P. 1994. Report on the NCWCD workshop on restoration of houbara bustard populations in Saudi Arabia. Re-introduction News, No. 8, 2-3. African Wildlife Foundation, Kenya.

Child, G. and Grainger, J. 1990. A system plan for protected areas for wildife conservation and sustainable development in Saudi Arabia. NCWCD, Riyadh, Saudi Arabia.

Collar, N.J. 1980. Bustards in decline. British Birds, 73, 198-199.

Combreau, O., Saint Jalme, M., Seddon, P., Rambaud, F., van Heezik, Y., Paillat, P., Gaucher, $P$. and Smith, $T$. In press. A programme for houbara bustard restoration in Saudi Arabia. In Proceedings of the First International Wildlife Management Congress. San José, Costa Rica, 1993.

Cramp, S. and Simmons, K.E.L. 1980. (eds). Handbook of the Birds of Europe, the Middle East and North Africa, Vol II. pp. 636-668. Oxford University Press, Oxford.

Gaucher, P., Paillat, P., Chappuis, C., Saint Jalme, M., Lotfikhah, F. and Wink, M. In prep. The taxonomy of the houbara bustard Chlamydotis undulata subspecies revisited on the basis of sexual display and genetic divergence.

Goriup, P. In press. Population management and habitat restoration of the houbara bustard. In Proceedings of the Symposium on the Restoration of Houbara Bustard Populations in Saudi Arabia. NCWCD, Riyadh, Saudi Arabia.

Gubin, B. In press. Status of the houbara bustard in Kazakhstan. In Proceedings of the Symposium on the Restoration of Houbara Bustard Populations in Saudi Arabia. NCWCD, Riyadh, Saudi Arabia.

IUCN. 1990. 1990 IUCN Red List of Threatened Animals. IUCN, Gland, Switzerland and Cambridge, UK.

Jennings, M.C. 1988. The former distribution of the houbara. Phoenix, 5, 4 .
Jennings, M.C. 1989. The birds of Saudi Arabia: past, present and future. In Wildlife Conservation and Development in Saudi Arabia. Proceedings of the First Symposium, Riyadh, 1987 (eds A. H. Abuzinada, P. D. Goriup and J. Nader) pp. 225-262. NCWCD, Riyadh, Saudi Arabia.

Peterson, R.T. 1948. Birds over America. Dodd, Mead \& Co., New York.

Renaud, J. 1989. Captive propagation of houbara bustards at the National Wildlife Research Center, Taif. In Wildlife Conservation and Development in Saudi Arabia. Proceedings of the First Symposium, Riyadh, 1987 (eds A. H. Abuzinada, P. D. Goriup and J. Nader) pp. 335-339. NCWCD, Riyadh, Saudi Arabia.

Saint Jalme, M. In press. Houbara bustard Chlamydotis undulata macqueeniii release perspectives in Saudi Arabia and population viability assessment. In Proceedings of the Symposium on the Restoration of Houbara Bustard Populations in Saudi Arabia. NCWCD, Riyadh, Saudi Arabia.

Saint Jalme, M., Combreau, O., Seddon, P., Paillat, P., Gaucher, P. and van Heezik, Y. In press, a. Restoration of houbara bustard populations in Saudi Arabia: a progress report. In Proceedings of the 5th Annual Conference of the Society for Ecological Restoration, 1993.

Saint Jalme, M., Gaucher, P. and Paillat, P. 1994. Artificial insemination in houbara bustards (Chlamydotis undulata): influence of the number of spermatozoa and insemination frequency on fertility and hatchibility. Journal of Reproductive Fertility. 100, 93-103.

Seddon, P.J. 1993. Species conseroation strategy for the houbara bustard (Chlamydotis undulata macqueeniii) in Saudi Arabia. First Draft. NCWCD, Riyadh, Saudi Arabia.

Seddon, P.J. and van Heezik, Y. In prep. Interseasonal changes in houbara bustard density and habitat utilization in Harrat al Harrah, Saudi Arabia.

Weigeldt, C., Schulz, H. and Paillat, P. 1991. Experimental release of houbara (Chlamydotis undulata macqueeniii) in Mahazat As Said. Unpubl. Report, NWRC, Taif, Saudi Arabia.

Philip J. Seddon, Michel Saint Jalme, Yolanda van Heezik, Patrick Paillat, Philippe Gaucher and Olivier Combreau, National Wildlife Research Center, National Commission for Wildlife Conservation and Development, PO Box 1086, Taif Saudi Arabia. 